\title{
Isolation and Quantification of Mimivirus-Like and Marseillevirus-Like Viruses from Soil Samples in An Aboriginal (Orang asli) Village in Peninsular Malaysia
}

\author{
Yeh Fong Tan ${ }^{\text {a Chai Ying Lim }}{ }^{\mathrm{a}}$ Chun Wie Chong $^{\mathrm{a}}$ Patricia Kim Chooi Lim ${ }^{\mathrm{a}}$ \\ Ivan Kok Seng Yap ${ }^{a}$ Pooi Pooi Leong ${ }^{b}$ Kenny Voon ${ }^{a}$

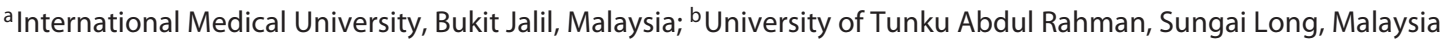

\section{Keywords}

Mimivirus · Orang asli · Marseillevirus

\begin{abstract}
Background: The giant amoebal viruses of Mimivirus and Marseillevirus are large DNA viruses and have been documented in water, soil, and sewage samples. The trend of discovering these giant amoebal viruses has been increasing throughout Asia with Japan, India, and Saudi Arabia being the latest countries to document the presence of these viruses. To date, there have been no reports of large amoebal viruses being isolated in South East Asia. Objective: In this study, we aim to discover these viruses from soil samples in an aboriginalvillage(Serendah village) in PeninsularMalaysia. Method and Results: We successfully detected and isolated both Mimivirus-like and Marseillevirus-like viruses using Acanthamoeba castellanii. Phylogeny analysis identified
\end{abstract}

(c) 2018 S. Karger AG, Basel

E-Mail karger@karger.com www.karger.com/int them as Mimivirus and Marseillevirus, respectively. Conclusion: The ubiquitous nature of both Mimivirus and Marseillevirus is further confirmed in our study as they are detected in higher quantity in soil that is near to water vicinities in an aboriginal village in Peninsular Malaysia. However, this study is limited by our inability to investigate the impact of Mimivirus and Marseillevirus on the aboriginal villagers. More studies on the potential impact of these viruses on human health, especially on the aborigines, are warranted.

(c) 2018 S. Karger AG, Base

\section{Background}

Giant amoebal viruses which were discovered over a decade ago comprised of 2 distinct families: Mimiviridae and Marseilleviridae. Viruses of the family Mimiviridae had been isolated and characterized with increasing fre- 


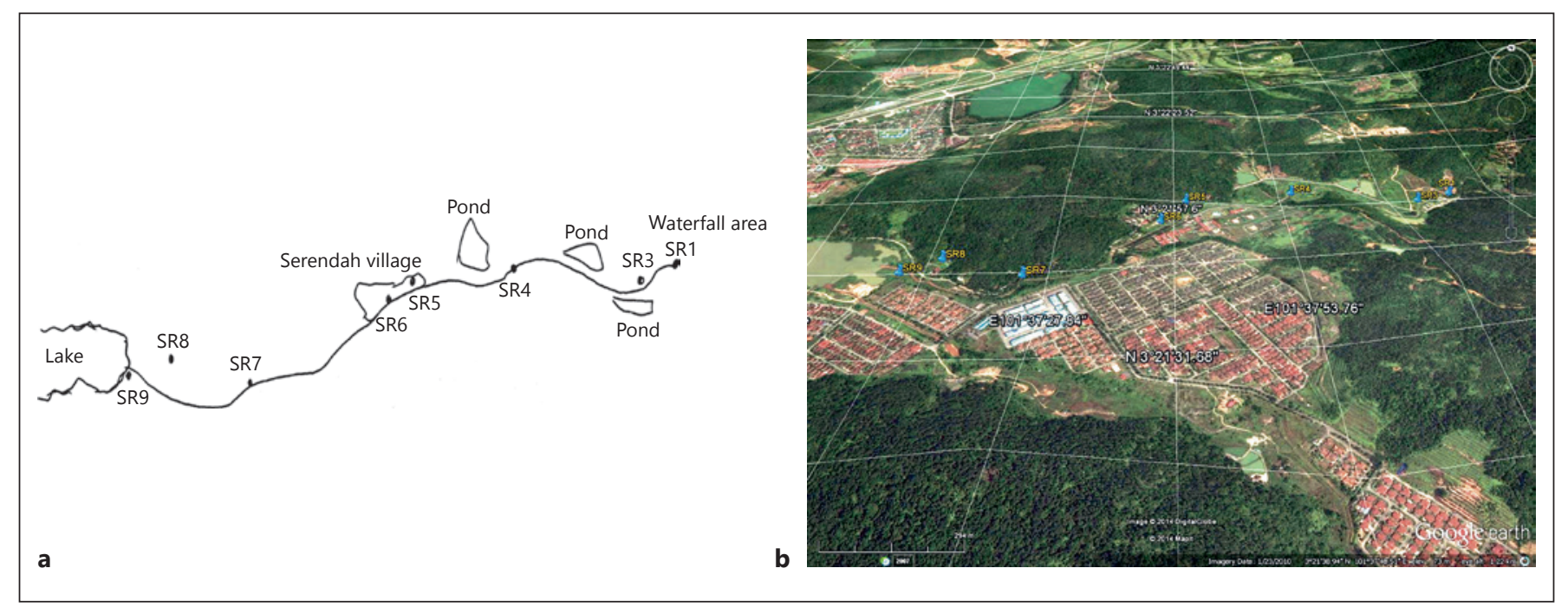

Fig. 1. Sampling sites at Serendah aboriginal village and its surrounding areas in sketch (a) and Google map (b). SR1-3, site of the waterfall (SR2 is midpoint between SR1 and SR3; not tagged in the map); SR4, midpoint between waterfall and village; SR5, village health clinic center located at top of a slope leading to the bank for a stream; SR6, football field; SR7, near a gravity toilet at top of a slope leading to the bank for the same stream; SR8, ex-construction site situated at an inclination; SR9, ex-agricultural land situated next to a stream opening out to a lake. (Adapted from Google Maps.) quency recently in Asian countries such as Japan, India, and Saudi Arabia [1-3]. However, at the time of writing, there were no reports of giant amoebal viruses detected in South East Asia. Due to the ubiquitous nature of giant amoebal viruses, both Mimivirus and Marseillevirus have been found in a wide range of environments. These include water samples from man-made structures like cooling tower and from natural sources like river, lake, or ocean [4-9]. They are also found in soil, on other animals like leech and oyster, and disturbingly, some on human samples [10-15]. In this paper, we describe the isolation and distribution both Mimivirus-like and Marseilleviruslike viruses from the Serendah Village, which is an aboriginal settlement in Peninsular Malaysia.

Nine sampling points (SR1-9) were tagged across Serendah village (Central Peninsular Malaysia; Fig. 1). For each sampling point, 9 samples were collected within a $500-\mathrm{m}$ radius of the point. These samples were pooled, transported in cold chain, and subsequently stored at $-80^{\circ} \mathrm{C}$. Isolation of Mimivirus or Marseillevirus was performed through blind passages on Acanthamoeba castellanii (ATCC 30010) until cytopathic effects (CPE) were observed. Infected Acanthamoeba castellanii were then Giemsa-stained to detect the viral factories. DNA was extracted from the pooled soil samples using TIANamp soil DNA kit (TIAN, China) according to the manufacturer's protocol. In those samples where Mimivirus-like or Mar- seillevirus-like viruses were successfully isolated, phylogeny was performed by using specific primers targeting the helicases of Mimivirus and Marseillevirus as previously described by Slimani et al. [16, 17]. DNA sequences were deposited in the Genbank (MG981284-7). Quantification of Mimivirus and Marseillevirus partial viral genome copies in the soil samples was performed as previously described by Ngounga et al. [18].

Out of the 9 sampling sites, 4 of them (SR1, 4, 5, and 9) were demonstrated to have CPE on the cultured Acanthamoeba castellanii after several rounds of blind passages. Viral inclusion factories were spotted in these cultures with CPE that were stained with Giemsa stain, indicating Mimivirus-like infection (see online suppl. Fig. S1; for all online suppl. material, see www.karger.com/ doi/10.1159/000491602). Further molecular identification through the construction of phylogenetic tree showed that Mimiviruses were detected on SR1, 4, and 9. The virus detected in SR5 belonged to Marseillevirus (Fig. 2). Quantification of the Mimivirus from all 9 sampling sites showed that these viruses were present in high levels in the respective soils where Mimiviruses were isolated (SR1, 4, and 9) and not in other sampling sites. Similarly, Marseillevirus was detected at a high level in SR5 (Fig. 3).

Although the impact of these viruses to the health of the Serendah village inhabitants is not known yet, there are of increasing evidences supporting that Mimiviruses 
Fig. 2. Phylogenetic tree demonstrating genetically close-relatedness of isolates SR1, 4, 9 (a), and SR5 (b) to Mimivirus and Marseillevirus, respectively. Neighbor joining tree was performed on helicase gene with bootstrap of 1,000 replicates. Accession numbers were stated on each taxa.
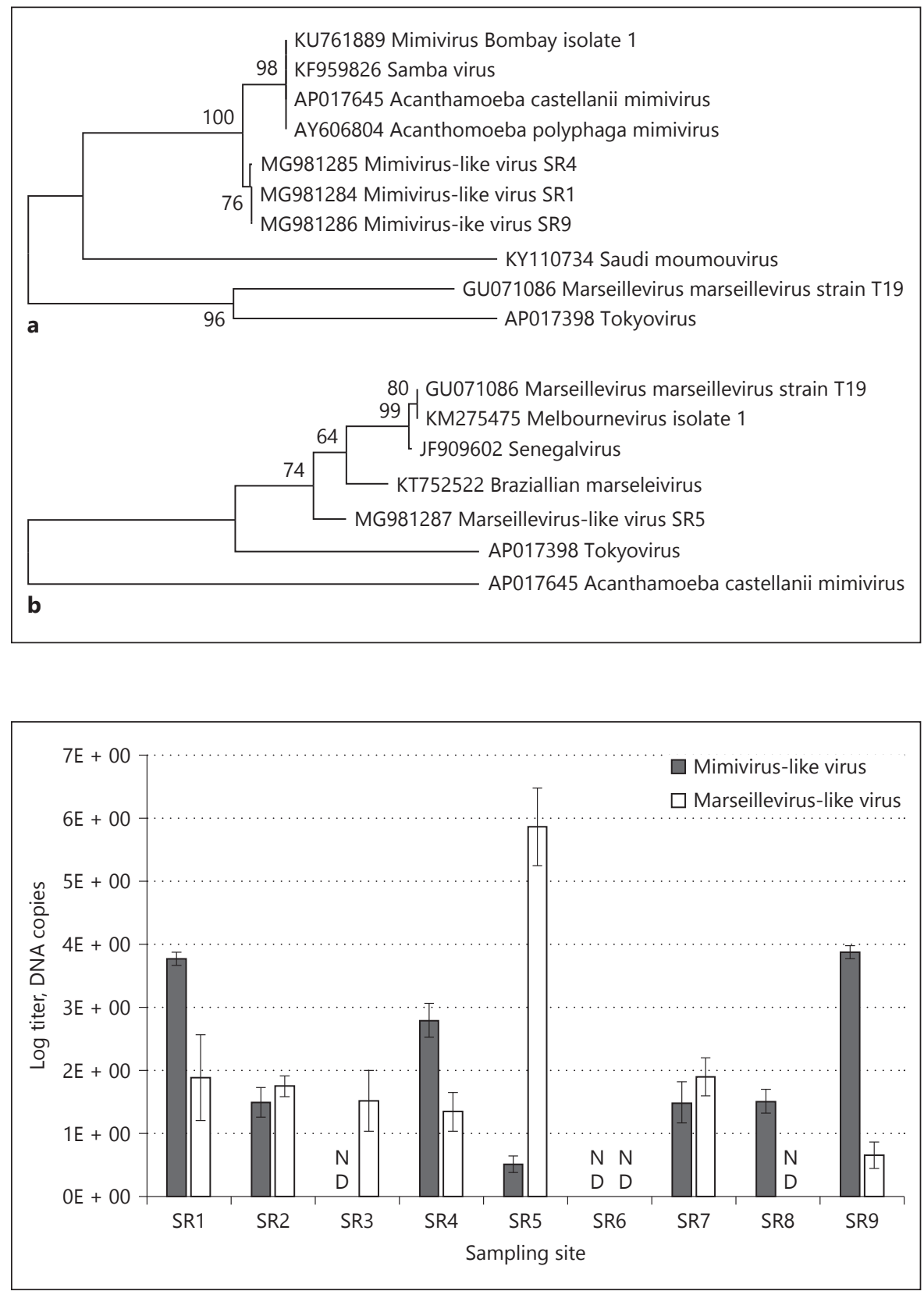

Fig. 3. Quantification of Mimivirus and Marseillevirus from soil samples. SR1, SR4, and SR9 showed higher Mimivirus DNA while SR5 showed higher Marseillevirus DNA compared to other sampling sites. $\mathrm{ND}$, not detectable. cially where water source is within the vicinities. The data indicated that viral titers were higher in soils (SR1, SR4, SR5, and SR9) which are near the water source and lower in samples further away from the water sources. Marseillevirus-like virus was isolated from soils collected at the vicinity of the health clinic (SR5), located on top of the slope leading to the bank of a stream. Similarly, Mimivirus-like virus was isolated from soils collected at the water fall (SR1), midway to the water fall (SR4), and ex-agricultural land (SR9) situated next to a stream opening out to a lake. To conclude, viruses of Mimiviridae were discov- 
ered in Peninsular Malaysia further supporting the ubiquitous nature of the Mimivirus and Marseillevirus. This study warrants a further investigation on the circulation and epidemiology of Mimiviridae in aboriginal settlements in Malaysia.

\section{Acknowledgments}

We are grateful to Dr Chan Li Li for her generosity in providing Acanthamoeba castellanii culture.

\section{Availability of the Data}

All data generated or analyzed during this study are included in this published article and its online supplementary Figure and Table.

\section{Ethics Approval}

This article does not contain any studies with human participants or animals performed by any of the authors.

\section{Authors Consents}

All authors consent for publication.

\section{Disclosure Statement}

All authors declare non-competing interest.

\section{Funding Source}

This study was funded by International Medical University (BP I-01/11(37)2014 and BPI-01/12(13)2015).

\section{Author's Contribution}

K.V. and C.W.C. designed the experiments; Y.F.T. and C.Y.L. contributed to sample processing, viral DNA extraction, PCR and subcloning; K.V. performed the viral culture. PLKC provided the helminths egg counts data. P.P.L. and K.V. provided essential reagents and helped write the paper; C.W.C. provided valuable suggestion. Y.F.T. and K.V. revised the paper. All authors read and approved the final manuscript.

\section{References}

1 Takemura M, Mikami T, Murono S: Nearly complete genome sequences of two mimivirus strains isolated from a Japanese freshwater pond and river mouth. Genome Announc 2016;4:pii e01378-16.

2 Chatterjee A, Ali F, Bange D, Kondabagil K: Isolation and complete genome sequencing of mimivirus Bombay, a giant virus in sewage of Mumbai, India. Genomics Data 2016;9:1-3.

3 Bajrai LH, de Assis FL, Azhar EI, Jardot P, Robert C, Abrahão J, et al: Saudi moumouvirus, the first group B mimivirus isolated from Asia. Front Microbiol 2016;7:2029.

4 Scola BL: A giant virus in amoebae. Science 2003;299:2033.

5 Boyer M, Yutin N, Pagnier I, Barrassi L, Fournous G, Espinosa L, et al: Giant Marseillevirus highlights the role of amoebae as a melting pot in emergence of chimeric microorganisms. Proc Natl Acad Sci U S A 2009;106: 21848-21853.

6 Assis FL, Bajrai L, Abrahao JS, Kroon EG, Dornas FP, Andrade KR, et al: Pan-genome analysis of Brazilian lineage a amoebal mimiviruses. Viruses 2015;7:3483-3499.

7 Thomas V, Bertelli C, Collyn F, Casson N, Telenti A, Goesmann A, et al: Lausannevirus, a giant amoebal virus encoding histone doublets. Environ Microbiol 2011;13:1454-1466.
8 Boratto PV, Arantes TS, Silva LC, Assis FL, Kroon EG, La Scola B, et al: Niemeyer virus: a new mimivirus group A isolate harboring a set of duplicated aminoacyl-tRNA synthetase genes. Front Microbiol 2015;6:1-11.

9 Arslan D, Legendre M, Seltzer V, Abergel C, Claverie JM: Distant Mimivirus relative with a larger genome highlights the fundamental features of Megaviridae. Proc Natl Acad Sci U S A 2011;108:17486-17491.

10 Yoosuf N, Pagnier I, Fournous G, Robert C, Raoult D, La Scola B, et al: Draft genome sequences of Terra1 and Terra2 viruses, new members of the family Mimiviridae isolated from soil. Virology 2014;452-453:125132.

11 Boughalmi M, Pagnier I, Aherfi S, Colson P, Raoult D, La Scola B: First isolation of a giant virus from wild Hirudo medicinalis leech: Mimiviridae isolation in Hirudo medicinalis. Viruses 2013;5:2920-2930.

12 Andrade KR, Boratto PP, Rodrigues FP, Silva LC, Dornas FP, Pilotto MR, et al: Oysters as hot spots for mimivirus isolation. Arch Virol 2014;160:477-482.

13 Saadi H, Pagnier I, Colson P, Cherif JK, Beji M, Boughalmi M, et al: First isolation of Mimivirus in a patient with pneumonia. Clin Infect Dis 2013;57:127-134.
14 Saadi H, Reteno DGI, Colson P, Aherfi S, Minodier P, Pagnier I, et al: Shan virus: a new mimivirus isolated from the stool of a Tunisian patient with pneumonia. Intervirology 2013;56:424-429.

15 Popgeorgiev N, Boyer M, Fancello L, Monteil S, Robert C, Rivet R, et al: Giant Blood Marseillevirus recovered from asymptomatic blood donors. J Infect Dis 2013;44:1-16.

16 SlimaniM,PagnierI,RaoultD,LaScolaB:Amoebae as battlefields for bacteria, giant viruses, and virophages. J Virol 2013;87:4783-4785.

17 Popgeorgiev N, Boyer M, Fancello L, Monteil S, Robert C, Rivet R, et al: Marseillevirus-like virus recovered from blood donated by asymptomatic humans. J Infect Dis 2013;208: 1042-1050

18 Ngounga T, Pagnier I, Reteno DGI, Raoult D, La Scola B, Colson P: Real-time PCR systems targeting giant viruses of amoebae and their virophages. Intervirology 2013;56:413-423.

19 La Scola B, Marrie TJ, Auffray JP, Raoult D: Mimivirus in pneumonia patients. Emerg Infect Dis 2005; 11:449-452.

20 Dornas FP, Rodrigues FP, Boratto PV, Silva LC, Ferreira PC, Bonjardim CA, et al: Mimivirus circulation among wild and domestic mammals, Amazon Region, Brazil. Emerg Infect Dis 2014;20:469-472. 